\title{
A Survey on Users' Perspectives to Functionalities of Web-Based Construction Collaboration Extranets
}

\author{
Nan Liu, Chongqing Jiaotong University, Chongqing, China \\ (iD) https://orcid.org/0000-0002-9626-1146 \\ Zhi Zeng, Chongqing Jiaotong University, Chongqing, China \\ Ruoyu Jin, University of Brighton, Brighton, England
}

\begin{abstract}
Construction collaboration extranets (CCEs) provide various functionalities depending on the vendors' origins, history, experiences, and financial status. Previous research has listed and described the functionalities that extranet systems can be capable of providing. However, no publication was found so far to systematically analyze users' perspectives to the provided functionalities. This article is to bridge this gap through a questionnaire survey to the users. It aims at examining user's attitude to functionalities of CCEs. The result may be useful to information system vendors, end-users and researchers involved in CCEs development and implementation.
\end{abstract}

\section{KEYWORDS}

Construction Collaboration Extranets, Functionality, Survey, User's Perception

\section{INTRODUCTION}

Web-based Construction collaboration extranets (CCEs), or sometimes called project extranets, have been adopted in improving the efficiency and effectiveness of information management, communication and collaboration in the construction industry (Becerik and Pollalis, 2006). CCEs make use of the advantages of the Internet for being a global network that is not restricted by location, time or different computer operating systems. The benefits gained from using CCEs include: no extra hardware and software investment (Zou and Roslan, 2005); application and location independent (Nitithamyong and Skibniewski, 2004); up-to-date information retrieval and improved communication (Zou and Roslan, 2005); cost and time effective (Tam, 1999, NCCTP, 2006); and some intangible benefits like few claims and greater flexibility (Wilkinson, 2005, Wilkinson, 2008).

To deliver these benefits to users, current CCEs have supplied a number of functions including document management tool, workflow management tool, collaborative tool, organizational tool, reporting and data exporting tool and maintenance tool (Zou and Roslan, 2005). The functionalities

DOI: $10.4018 / \mathrm{IJeC} .2019100101$

Copyright $\odot$ 2019, IGI Global. Copying or distributing in print or electronic forms without written permission of IGI Global is prohibited. 
supplied by a certain product vary greatly depending on the origins, history, and financial status of the vendors (Wilkinson, 2005), in the form of a single service to fully hosted service (CICA, 2003).

Previous studies have attempted to gather the functionalities of CCEs (Nitithamyong and Skibniewski, 2004, Wilkinson, 2005, Becerik, 2004), produce a features list or check list (CICA, 2003, Breetzke and Hawkins, 2002), and analyze their availability and distribution in some sample systems (Liu et al., 2011). These works were helpful to identify the available functionalities of CCEs but they were mainly from the system vendors and didn't reflect the users' perspectives. In this regard, Ruikar et al. (2005) had tried to gain an insight from the users' perspectives on the use of such systems. Lin et al (2013) studied the factors effecting on user satisfaction. But no publication was found to study the users' attitude or choices on the functionalities that CCEs are capable of providing. This is unsatisfactory as effective function management is particularly crucial for the end-users to understand the functionalities provided by the respective systems prior to adopting and implementing the technology, as selecting wrong system will surely result in time-wasting and other costly problems (Raol et al., 2002).

This paper is an attempt aiming to investigate from users perspectives based on a questionnaire survey. The results will provide an empirical evidence of user needs to functionalities of CCEs

\section{FUNCTIONALITIES OF CCES}

In CCEs, the main and purposeful function is to share project documents among project participants. Current systems are not only allowing sharing the documents through the network, but also enabling users to manage the files locally or remotely without installing any extra software. In addition, the latest CCEs provide many supporting or additional functions to facilitate the information transfer and communication tasks, to streamline the workflow and to collaborate with the other partners during construction process, with some customized environments. Some extra functional modules, e.g. e-tendering service, are introduced to the systems and provide additional functionalities to the end-users.

In this research, the authors use the categorization given in Liu et al. (2011), which grouped all functionalities into 4 categories: System administration, Document management, Workflow management and Communication tools plus add-ons. The hierarchical and interrelated structure of CCE, functions and features can be illustrated as Figure 1. More details about the functions and features can be found in Liu et al. (2011) and Charalambous et al. (2012).

\section{RESEARCH METHODOLOGIES}

\subsection{The Questionnaire Survey}

Survey is a commonly used method for behavioural research (Sommer and Sommer, 2002), via a lot of methods, such as interviewing, questionnaires, or by observation (Zowghi and Coulin, 2005). In this research, the authors adopted questionnaire survey to capture users' perspectives to CCEs functionalities.

The questionnaire of this research was divided into three main sections. Section one (title and introduction) aims to explain what this research is for and how this survey is undertaken. It also encourages the respondents to continue completing this questionnaire survey. Section 2 (general information) is concerned with the collection of general information of the respondents and their organizations. Section 3 (user attitude elicitation) is the major part and is aiming at the actual goal of this survey. The question asked and all items in questions in line with the functions and associated features given in Figure 1. In addition, a thank-you part and returned methods are attached to the last part of the questionnaire. 


\section{CCE}

\begin{tabular}{|c|}
\hline $\begin{array}{c}\text { System } \\
\text { administration }\end{array}$ \\
\hline $\begin{array}{l}\text { - User profiling / } \\
\text { User directory } \\
\text { - Project panel } \\
\text { - Multi-project } \\
\text { - Customization } \\
\text { - Project inbox } \\
\text { - Template } \\
\text { - Access monitor } \\
\text { - Hand-held device } \\
\text { - Security } \\
\text { - Localization } \\
\text { - Client-end software }\end{array}$ \\
\hline
\end{tabular}

\begin{tabular}{|l|}
\hline \multicolumn{1}{|c|}{$\begin{array}{c}\text { Document } \\
\text { management }\end{array}$} \\
\hline - File up/download \\
- File encryption \\
- File sharing \\
- Remote viewing \\
- Mark-up/ revise \\
- Notification of \\
- change \\
- Search tool \\
- Prack record \\
- Multi-format \\
- File archival \\
- Workflowintegration \\
- Disaster protection \\
\hline
\end{tabular}

\section{Workflow and task management}
- Project calendar
- Process management
- TQ, RFI management
- Change order / approval
- Real-time event management
- Report on workflow

\section{Communication} and add-ons.

- E-mail

- Instant messenger

- Discussion forum

- Audio/video conference.

- E-Tendering/ bidding

- Health \& Safety file

The respondents groups in the survey were defined as architect and contractors. The reasons are follows: 1 . the documents produced by architects are often the core materials in construction process. 2. the mobility of contractors often add difficulties on the information transfer and communication during construction process, which makes the study much more crucial.

\subsection{Statistical Analysis}

After the questionnaire survey, multivariate statistical methods were used to analyze the survey data, including the reliability analysis of the overall scale and subscales of the questionnaire survey, and the one-way analysis of variance (ANOVA) for the grouping of respondents' organizational types and organizational sizes.

\subsubsection{The Reliability Analysis}

In order to check the reliability of survey data, it is necessary to analyze the reliability of survey data. Cronbach's alpha reliability coefficient is the most commonly used reliability coefficient, and its formula is shown in Equation (1):

$\alpha=(\mathrm{k} /(\mathrm{k}-1)) *\left(1-\left(\sum \mathrm{Si}^{\wedge} 2\right) / \mathrm{ST}^{\wedge} 2\right)$

where $\mathrm{K}$ is the total number of items in the scale, $\mathrm{Si}^{\wedge} 2$ is the intra-item variance of the score of item $\mathrm{I}$, and $\mathrm{ST}^{\wedge} 2$ is the variance of the total score of all items.

It can be seen from Equation (1) that alpha coefficient evaluates the consistency between scores of each item in the scale, which contributes to the internal consistency coefficient. This method is suitable for reliability analysis of attitude and opinion questionnaire (scale). The reliability coefficient of the total scale should be above 0.8 , and between 0.7 and 0.8 is acceptable. The reliability coefficient of the subscale should be above 0.7 , and between 0.6 and 0.7 is acceptable. If the Cronbach's alpha coefficient is below 0.6, the questionnaire should be re-compiled (Gliem and Gliem, 2003). 


\subsubsection{Analysis of Variance (ANOVA)}

ANOVA is usually used to test the significance of the difference between two or more samples (Girden, 1992). In this survey, one-way ANOVA is used to study whether different levels of a control variable have significant influence on the observed variable. The survey sample was divided into different groups according to the type and size of the organizations that respondents belonged to. One-way ANOVA was used to analyze the survey samples to test whether different organizational types or organizational sizes had significant influences on the functional requirements of respondents in the four aspects of CCEs, i.e., system management, document management, workflow management, and communication and attachment. The null hypothesis was set that different organization types or organization sizes had no significant impact on the functional requirements of respondents in CCEs. The level of significance was set at 0.05 . If the significance was lower than 0.05 , the null hypothesis would be rejected, and it would be indicated that different organization types or organization sizes had significant influences on the functional needs of respondents in CCEs.

\section{DATA COLLECTION AND FINDINGS}

As soon as questionnaire was finalized and pilot study was completed, survey was undertaken between July 2011 and April 2012. The questionnaires were distributed to architectural firms and contractor corporations randomly selected from local yellow pages in Chongqing, China. The distribution was mainly done by postal mail, and email mailing list. To increase the response rate, one-to-one administration was adopted, i.e. personal network and face-to-face visit were used to access more respondents. A total of 600 copies of questionnaire were distributed. Totally 158 copies were returned and 103 copies were considered valid for this research after 45 copies were screened out due to incompleteness.

\subsection{The Reliability Analysis}

SPSS software was used to conduct reliability analysis on the survey samples, and the analysis results were shown in Table 1. It can be seen from Table 1 that the overall Cronbach's alpha reliability coefficient is 0.851 , greater than 0.8 . And Cronbach's alpha reliability coefficients of the questionnaire subscale are all greater than 0.8 , so indicating that the questionnaire responses have a high reliability and are acceptable.

\subsection{Profile of Respondents}

The profile of respondents includes the organization's size, type and the respondents' position in organizations. Figure 2 shows the organizations' size which is classified as three groups to meet the definition of European Commissions to SME and large enterprise. The result indicates that there is no bias for the organization's size. Figure 3 shows that respondents are mainly from the architectural firms (17\%) and contractors (35\% for general contractors and $17 \%$ for subcontractors), which consist of $69 \%$ respondents in total. It is indicated that the respondents are mostly falling into the research's target groups. Figure 4 shows the positions of respondents in their organizations. Most respondents consist of construction project managers (24\%), engineers (17\%), architects (14\%) and researchers / analyst (14\%). They are normally in the frontline if using CCEs and therefore the respondents have well represented the targeted users.

\subsection{Users' Needs in Functionalities for CCEs}

In the questionnaire, respondents were asked to choose the essential features in each function module from their own opinion. The question items were in multiple responses style and percentage of all cases was used for later analysis. 
Table 1. Reliability analysis of questionnaire quantity scale and subscale

\begin{tabular}{|c|c|c|c|}
\hline Item & $\begin{array}{c}\text { Scale Variance if Item } \\
\text { Deleted }\end{array}$ & $\begin{array}{c}\text { Corrected Item-Total } \\
\text { Correlation }\end{array}$ & Cronbach's Alpha \\
\hline Other & 64.251 & 0.183 & 0.821 \\
\hline Client-end software support & 62.544 & 0.330 & 0.818 \\
\hline $\begin{array}{l}\text { Localization / multi- } \\
\text { languages }\end{array}$ & 60.865 & 0.517 & 0.813 \\
\hline Security & 64.186 & 0.145 & 0.822 \\
\hline Hand-held devices support & 62.172 & 0.137 & 0.828 \\
\hline Access control / monitor & 64.067 & 0.117 & 0.823 \\
\hline Project wizard / template & 60.843 & 0.519 & 0.813 \\
\hline Project inbox / notice board & 62.347 & 0.323 & 0.818 \\
\hline $\begin{array}{l}\text { Customization of project } \\
\text { web }\end{array}$ & 63.141 & 0.226 & 0.820 \\
\hline Multi-projects support & 62.867 & 0.309 & 0.819 \\
\hline Project panel / dashboard & 62.913 & 0.251 & 0.820 \\
\hline $\begin{array}{l}\text { User directory / address } \\
\text { book }\end{array}$ & 60.377 & 0.582 & 0.811 \\
\hline User hierarchical profiling & 61.252 & 0.491 & 0.814 \\
\hline Other & 65.057 & 0.022 & 0.823 \\
\hline Disaster protection & 60.589 & 0.555 & 0.812 \\
\hline Workflow integration & 63.799 & 0.157 & 0.822 \\
\hline File storage and archival & 61.425 & 0.450 & 0.815 \\
\hline Multi-format files support & 61.804 & 0.394 & 0.816 \\
\hline Printing-out & 61.252 & 0.465 & 0.814 \\
\hline Track record and history & 60.639 & 0.553 & 0.812 \\
\hline Search tools & 61.525 & 0.469 & 0.815 \\
\hline $\begin{array}{l}\text { Notification of change / } \\
\text { new }\end{array}$ & 61.087 & 0.490 & 0.814 \\
\hline Mark-up / revise & 60.360 & 0.586 & 0.811 \\
\hline Remote viewing & 60.687 & 0.542 & 0.812 \\
\hline File sharing / publishing & 61.784 & 0.487 & 0.815 \\
\hline File encryption & 64.487 & 0.053 & 0.825 \\
\hline File upload / download & 62.063 & 0.430 & 0.816 \\
\hline Other & 64.775 & 0.099 & 0.822 \\
\hline Report on workflow & 61.246 & 0.466 & 0.814 \\
\hline $\begin{array}{l}\text { Real-time event } \\
\text { management }\end{array}$ & 62.179 & 0.345 & 0.817 \\
\hline Change order and approval & 59.416 & 0.711 & 0.808 \\
\hline TQ, RFI Management* & 61.533 & 0.436 & 0.815 \\
\hline
\end{tabular}


Table 1. Continued

\begin{tabular}{|l|l|l|l|}
\hline \multicolumn{1}{|c|}{ Item } & \multicolumn{1}{|c|}{$\begin{array}{c}\text { Scale Variance if Item } \\
\text { Deleted }\end{array}$} & \multicolumn{1}{|c|}{$\begin{array}{c}\text { Corrected Item-Total } \\
\text { Correlation }\end{array}$} & \multicolumn{1}{|c|}{ Cronbach's Alpha } \\
\hline Process management & 64.036 & 0.120 & 0.823 \\
\hline Integrated project calendar & 63.290 & 0.224 & 0.820 \\
\hline Other & 64.410 & 0.230 & 0.821 \\
\hline Health \& Safety files & 61.724 & 0.474 & 0.815 \\
\hline e-Tendering / bidding & 61.925 & 0.384 & 0.816 \\
\hline WebCam facility & 62.989 & 0.263 & 0.820 \\
\hline Audio / Video conferencing & 64.923 & 0.003 & 0.826 \\
\hline Discussion forum / group & 62.063 & 0.366 & 0.817 \\
\hline Instant messenger (IM) & 65.309 & 0.048 & 0.827 \\
\hline E-mail & 63.808 & 0.199 & 0.821 \\
\hline The total scale & & & 0.851 \\
\hline
\end{tabular}

Figure 2. Organization's size

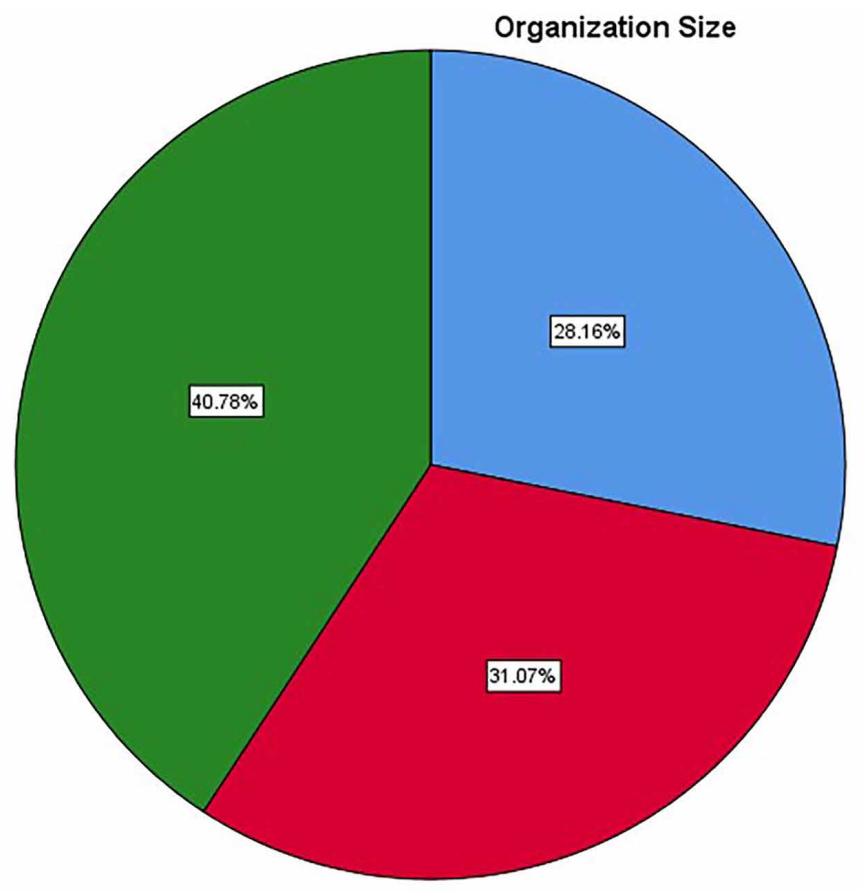

\subsubsection{System Administration}

From Figure 5, it is found that most respondents (75.2\%) require the feature of multi-projects support. More than half of them take user profiling / authorization, user directory / address, project control panel / dashboard, access control / usage monitor and Security features as essential ones. The higher rates of these feature options indicate that the users emphasize the system's usability, feasibility and 


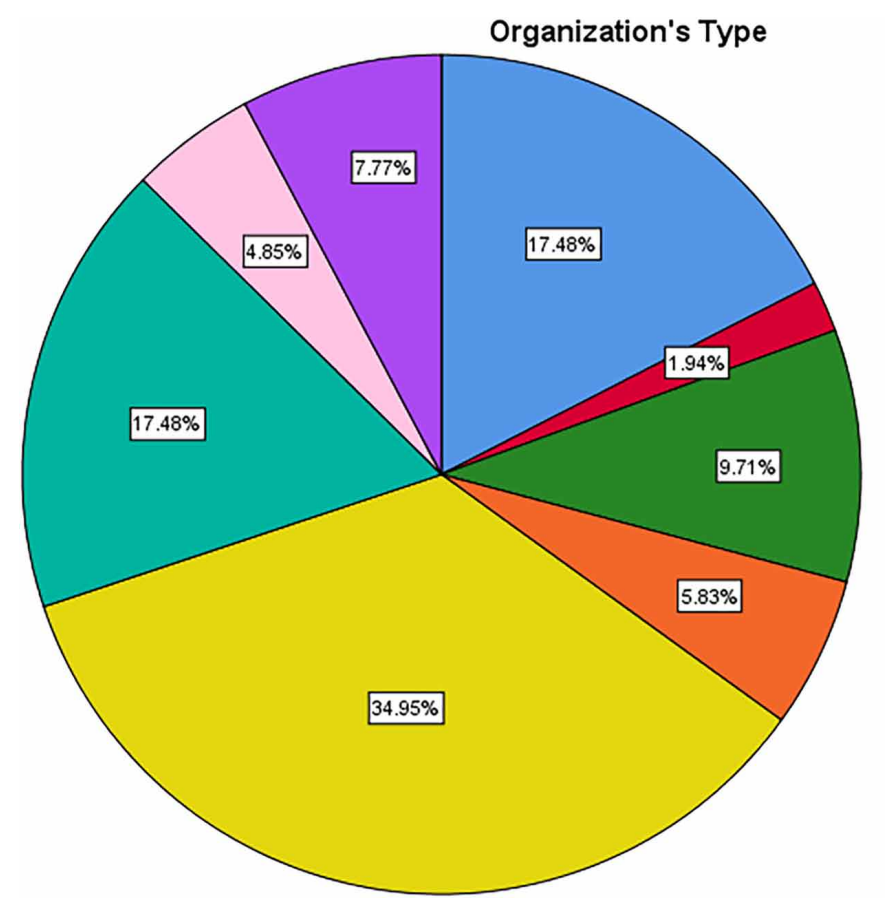

$\square$ Architectural firm

$\square$ Engineering firm $\square$ Client

$\square$ Consulting firm

$\square$ General contractor

$\square$ Sub-contractor

$\square$ Supplier

$\square$ Research institution

Figure 4. Respondents' position in organizations

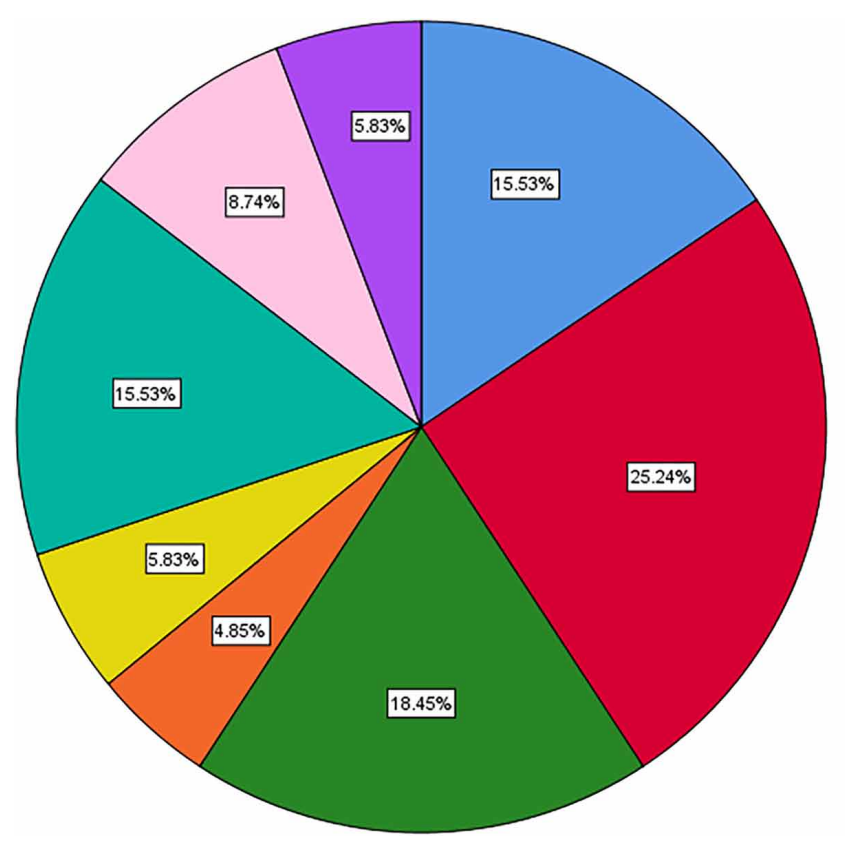

\section{Position in Organization}

$\square$ Architect

$\square$ Construction project manager

$\square$ Engineer

$\square$ Surveyor

$\square$ Supervisor

$\square$ Researcher / analyst

$\square$ IT manager / technician

$\square$ Other 
Figure 5. Frequencies of features associated with system administration

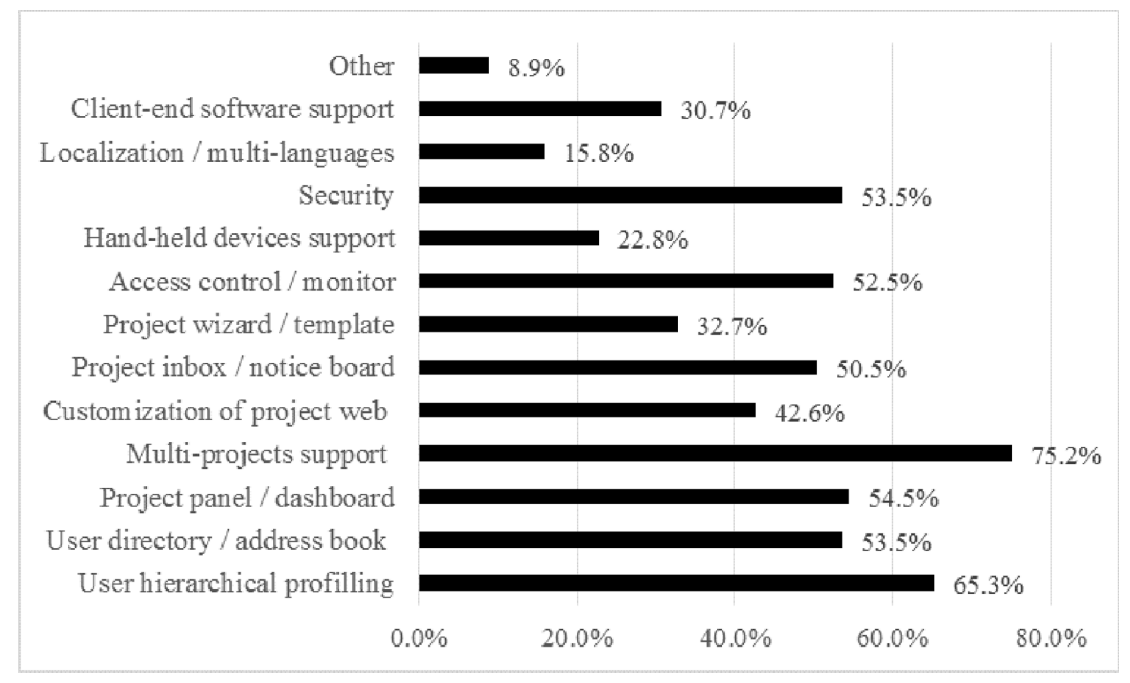

security. The features of designing a project web (customization of project web and project wizard / template) get fewer rates. This implies that respondents are confident in using this technology and can do this designing job with less help. It somewhat reflects the users' maturity in using the universal information technologies. This can also be proved from the lower need to client-end software. Actually, CCEs are not a creative technology other than generic internet browser with some plug-ins. So, the users should have no major obstacle in using this type of web-based information systems. Furthermore, the respondents show an interest in handheld devices support as there are around $20 \%$ respondents taking this as an essential feature. Finally, due to geographical restriction of construction industry, the participants are not so interested in the Localization of CCEs.

According to the organization type and organization size of the whole survey sample, one-way ANOVA is conducted for users' functional requirements of system management, as shown in Table 2. As can be seen from Table 2, except for project inbox / notice board and other features, which are related to the organizational size of respondents, the general views on system management functions are consistent. user hierarchical profiling, multi-projects support, project inbox / notice board, project wizard / template and access control / monitor are related to the organizational types of respondents, and respondents have the same views on the other functions.

\subsubsection{Document Management}

Of all 14 feature options in this function module, 10 have been selected by more than $50 \%$ respondents and the others get positive feedbacks as well. It indicates that, as the principle function of CCEs, almost all the features associated to this function are required by the users. Among them, file transfer, sharing and searching are the most wanted features, while file encryption, notification, track, printing and storage get also high scores. It implies the users have the strong needs in sharing, renewing and processing the document. In addition, nearly half of respondents select remote viewing, mark / revise and multi-format support as essential features. This is understandable considering the mobile and fragmented nature of construction process. Finally, workflow integration gets the lowest score. However, the authors assume it doesn't mean this feature is not important as there are still nearly one third respondents selecting this feature. It may be because that this feature is still new and is not widely acknowledged by the users (see Figure 6). 
Table 2. One-way ANOVA was conducted for user requirements of system management functions according to organization size and organization type

\begin{tabular}{|c|c|c|c|c|c|}
\hline \multirow[t]{2}{*}{ Item } & \multirow[t]{2}{*}{ Mean } & \multicolumn{2}{|c|}{$\begin{array}{c}\text { ANOVA of System Management } \\
\text { Function Survey Data Grouped } \\
\text { by Organization Size }\end{array}$} & \multicolumn{2}{|c|}{$\begin{array}{c}\text { ANOVA of System Management } \\
\text { Function Survey Data Grouped } \\
\text { by Organization Type }\end{array}$} \\
\hline & & $\mathbf{F}$ & Sig. & $\mathbf{F}$ & Sig. \\
\hline Other & 0.09 & 3.809 & $0.025^{*}$ & 0.416 & 0.890 \\
\hline Client-end software support & 0.30 & 0.181 & 0.835 & 1.558 & 0.158 \\
\hline Security & 0.16 & 2.095 & 0.128 & 1.115 & 0.360 \\
\hline Localization / multi-languages & 0.52 & 0.142 & 0.867 & 1.096 & 0.372 \\
\hline Hand-held devices support & 0.30 & 0.901 & 0.409 & 0.636 & 0.725 \\
\hline Project wizard / template & 0.51 & 0.675 & 0.512 & 2.322 & $0.031 *$ \\
\hline Access control / monitor & 0.32 & 0.578 & 0.563 & 3.907 & $0.001 *$ \\
\hline Project inbox / notice board & 0.50 & 4.541 & $0.013^{*}$ & 3.600 & $0.002 *$ \\
\hline Customization of project web & 0.42 & 0.437 & 0.647 & 1.364 & 0.230 \\
\hline Multi-projects support & 0.76 & 2.522 & 0.085 & 2.693 & $0.014^{*}$ \\
\hline Project panel / dashboard & 0.49 & 0.542 & 0.583 & 1.553 & 0.159 \\
\hline User directory / address book & 0.53 & 0.534 & 0.588 & 1.830 & 0.090 \\
\hline User hierarchical profiling & 0.65 & 2.537 & 0.084 & 3.808 & $0.001 *$ \\
\hline
\end{tabular}

Note: If sig. Is lower than 0.05 , there is significant difference in the views of different groups on this item

Figure 6. User's preference in document management

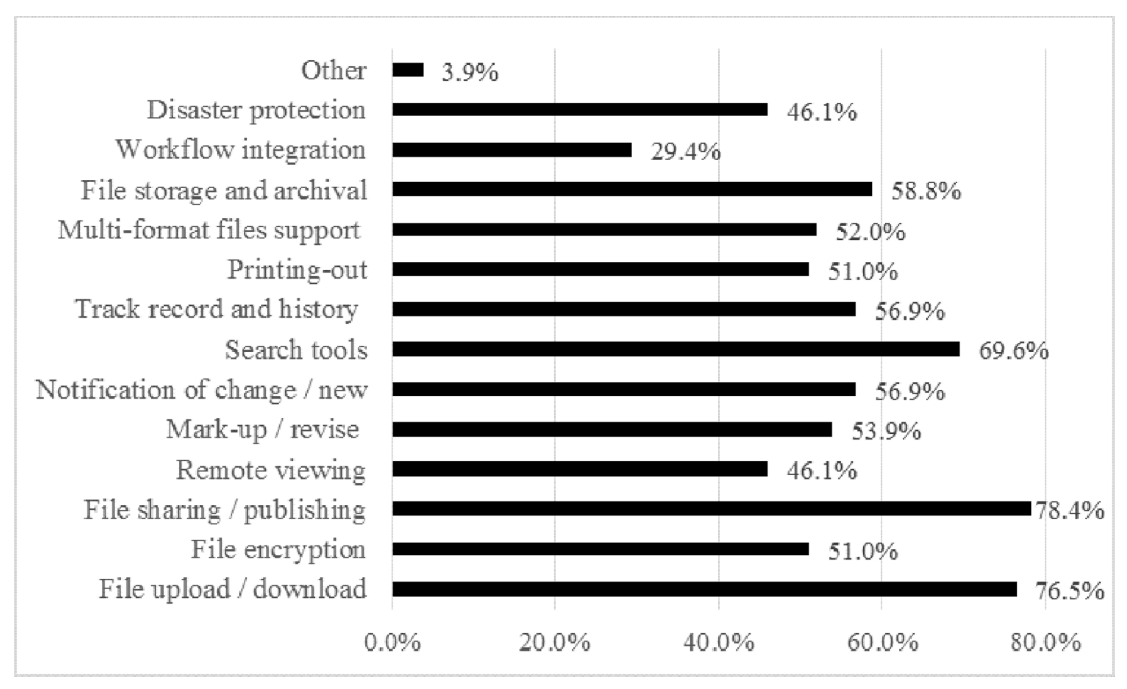

According to the organization type and organization size of the whole survey sample, one-way ANOVA was conducted for users' functional requirements of document management, as shown in Table 3. As can be seen from Table 3, file upload / download, remote viewing, notification of change / new and printing-out in the document management function are significantly different among groups divided by organizational size. And there are significant differences between groups divided 
Table 3. One-way ANOVA was conducted for user requirements of document management functions according to organization size and organization type

\begin{tabular}{|l|l|l|l|l|l|}
\hline \multirow{2}{*}{ Item } & \multirow{2}{*}{ Mean } & \multicolumn{2}{c|}{$\begin{array}{c}\text { ANOVA of Document } \\
\text { Management Function Survey } \\
\text { Data Grouped by Organization } \\
\text { Size }\end{array}$} & \multicolumn{2}{c|}{$\begin{array}{c}\text { ANOVA of Document } \\
\text { Management Function Survey } \\
\text { Data Grouped by Organization } \\
\text { Type }\end{array}$} \\
\cline { 3 - 7 } & \multicolumn{2}{|c|}{ F } & \multicolumn{2}{c|}{ F } & \multicolumn{2}{c|}{ Sig. } \\
\hline Other & 0.04 & 0.858 & 0.427 & 0.659 & 0.706 \\
\hline Disaster protection & 0.46 & 2.105 & 0.127 & 2.934 & $0.008^{*}$ \\
\hline Workflow integration & 0.30 & 1.221 & 0.299 & 1.018 & 0.424 \\
\hline File storage and archival & 0.58 & 0.488 & 0.615 & 1.099 & 0.370 \\
\hline Multi-format files support & 0.51 & 1.385 & 0.255 & 2.334 & $0.030^{*}$ \\
\hline Printing-out & 0.50 & 4.184 & $0.018^{*}$ & 3.922 & $0.001^{*}$ \\
\hline Track record and history & 0.57 & 1.490 & 0.230 & 2.045 & 0.057 \\
\hline Search tools & 0.69 & 2.139 & 0.123 & 2.226 & $0.039^{*}$ \\
\hline Notification of change / new & 0.55 & 4.597 & $0.012^{*}$ & 3.229 & $0.004^{*}$ \\
\hline Mark-up / revise & 0.54 & 0.493 & 0.612 & 2.634 & $0.016^{*}$ \\
\hline Remote viewing & 0.46 & 4.306 & $0.016^{*}$ & 3.275 & $0.004^{*}$ \\
\hline File sharing / publishing & 0.78 & 0.526 & 0.593 & 1.663 & 0.127 \\
\hline File encryption & 0.50 & 0.439 & 0.646 & 1.877 & 0.082 \\
\hline File upload / download & 0.76 & 5.557 & $0.005^{*}$ & 7.186 & $0.000^{*}$ \\
\hline
\end{tabular}

Note: If sig. Is lower than 0.05 , there is significant difference in the views of different groups on this item

by organizational types for file upload / download, remote viewing, mark-up / revise, notification of change / new, search tools, printing-out, multi-format files support and disaster protection in document management functions.

\subsubsection{Workflow Management}

In this function module, around two third of respondents select calendar and process management features as essential ones. This implies that the users pay much emphasis on the smooth and in-time construction process management. This can also be proved from the third higher rating of real-time event management. To keep the work going smoothly and avoid further dispute, the users also need the feature of recording change order and report on workflow (see Figure 7).

According to the organization type and organization size of the whole survey sample, one-way ANOVA of users' functional requirements in workflow management was conducted, as shown in Table 4. As can be seen from Table 4, only Process management has significant differences in users' views on workflow management functional requirements, while the remaining features have the same views. And there are significant differences among the groups divided by organizational type in the users' views on Integrated project calendar, Report on workflow, and Other features.

\subsubsection{Communication and Add-Ons}

The last function module is communication and add-ons. It is found that most of respondents (83.3\%) take email as the essential feature in the systems. But their choices in other features are much dispersed. None of the rest features are selected by more than half of respondents. On the one hand, this suggests that the users stick on the communication mean to their traditional and popular tools. On the other 
Figure 7. User's preference in workflow management

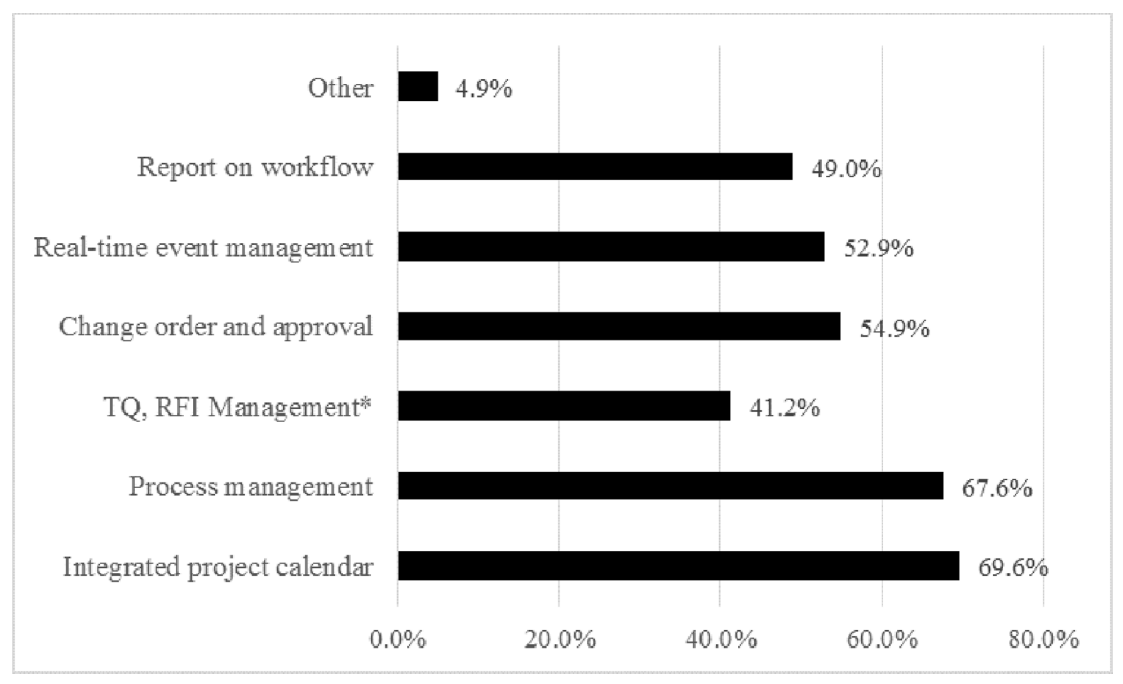

Table 4. One-way ANOVA was conducted for user requirements of workflow management functions according to organization size and organization type

\begin{tabular}{|c|c|c|c|c|c|}
\hline \multirow[t]{2}{*}{ Item } & \multirow[t]{2}{*}{ Mean } & \multicolumn{2}{|c|}{$\begin{array}{c}\text { ANOVA of Workflow Management } \\
\text { Function Survey Data Grouped by } \\
\text { Organization Size }\end{array}$} & \multicolumn{2}{|c|}{$\begin{array}{c}\text { ANOVA of Workflow Management } \\
\text { Function Survey Data Grouped by } \\
\text { Organization Type }\end{array}$} \\
\hline & & $\mathbf{F}$ & Sig. & $\mathbf{F}$ & Sig. \\
\hline Other & 0.05 & 1.772 & 0.175 & 9.906 & $0.000^{*}$ \\
\hline Report on workflow & 0.49 & 0.542 & 0.583 & 2.916 & $0.008^{*}$ \\
\hline Real-time event management & 0.52 & 0.703 & 0.498 & 0.672 & 0.695 \\
\hline Change order and approval & 0.53 & 1.609 & 0.205 & 1.442 & 0.198 \\
\hline TQ, RFI Management* & 0.42 & 0.610 & 0.545 & 1.535 & 0.165 \\
\hline Process management & 0.67 & 3.501 & $0.034 *$ & 1.384 & 0.221 \\
\hline Integrated project calendar & 0.69 & 1.678 & 0.192 & 4.462 & $0.000 *$ \\
\hline
\end{tabular}

Note: If sig. Is lower than 0.05 , there is significant difference in the views of different groups on this item

hand, it also proves that the features in this module are optional or unnecessary for presenting in the systems (see Figure 8).

Though, it is found that, among all optional features, e-Tendering seemed have better potential as more than $40 \%$ respondents regarded it as essential feature. This feature may be a must-have feature in the future products or becomes a separate product for sale. In this regard, Lou and Alshawi (2008) have confirmed in their research the application of E-Tendering systems in construction.

According to the organization type and organization size of the whole survey sample, one-way ANOVA was conducted on users' communication and attachment functional requirements, as shown in Table 5. As can be seen from Table 5, there are significant differences in users' views on E-mail, Instant messenger (IM), e-Tendering / bidding and Other features in communication and attachment functions among groups divided by organization size. And there are significant differences in users' views on E-mail, Instant messenger (IM), Discussion forum / group, WebCam facility, e-Tendering / 
Figure 8. User's preference in communication and add-ons

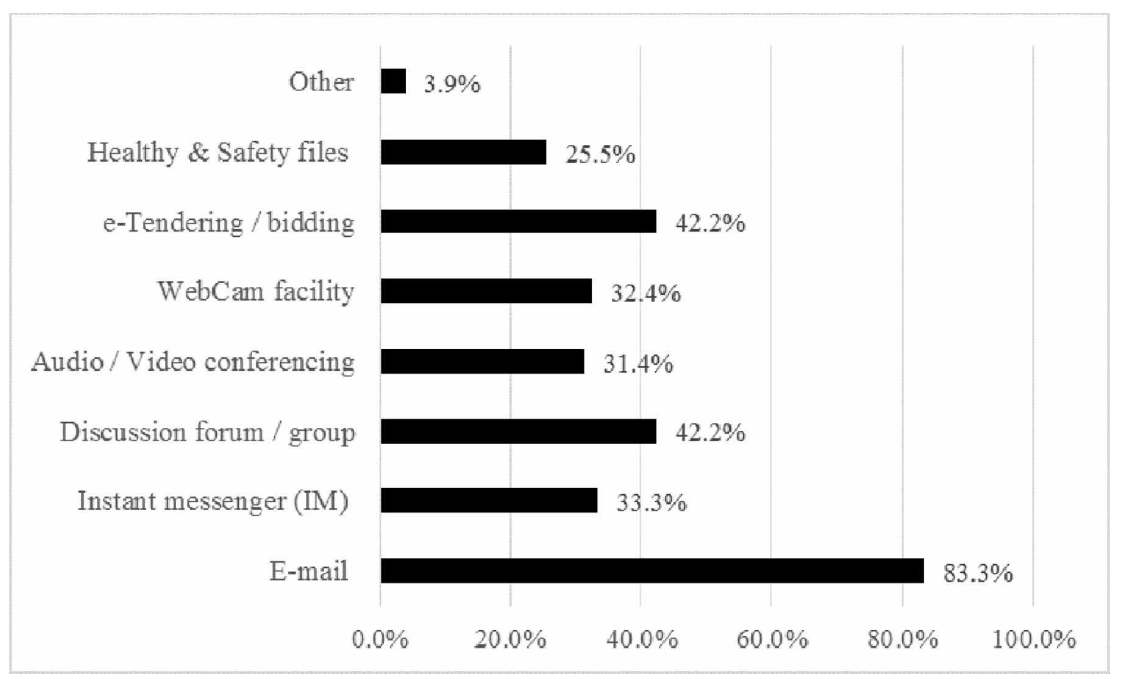

Table 5. One-way ANOVA was conducted for user requirements of communication and additional functions according to organization size and organization type

\begin{tabular}{|c|c|c|c|c|c|}
\hline \multirow[t]{2}{*}{ Item } & \multirow[t]{2}{*}{ Mean } & \multicolumn{2}{|c|}{$\begin{array}{l}\text { ANOVA of Communication and } \\
\text { Additional Function Survey Data } \\
\text { Grouped by Organization Size }\end{array}$} & \multicolumn{2}{|c|}{$\begin{array}{l}\text { ANOVA of Communication and } \\
\text { Additional Function Survey Data } \\
\text { Grouped by Organization Type }\end{array}$} \\
\hline & & $\mathbf{F}$ & Sig. & $\mathbf{F}$ & Sig. \\
\hline Other & 0.04 & 5.748 & $0.004 *$ & 0.552 & 0.793 \\
\hline Healthy \& Safety files & 0.25 & 1.312 & 0.274 & 4.073 & $0.001 *$ \\
\hline e-Tendering / bidding & 0.42 & 3.976 & $0.022 *$ & 2.401 & $0.026^{*}$ \\
\hline WebCam facility & 0.32 & 0.183 & 0.833 & 3.096 & $0.006^{*}$ \\
\hline Audio / Video conferencing & 0.31 & 0.527 & 0.592 & 1.733 & 0.111 \\
\hline Discussion forum / group & 0.42 & 1.070 & 0.347 & 2.540 & $0.019^{*}$ \\
\hline Instant messenger (IM) & 0.33 & 18.190 & $0.000 *$ & 2.507 & $0.021^{*}$ \\
\hline E-mail & 0.83 & 3.825 & $0.025^{*}$ & 3.051 & $0.006^{*}$ \\
\hline
\end{tabular}

Note: A sig. lower than 0.05 indicates that there is significant difference in the views of different groups on this item

bidding, and Health \& Safety files in communication and attachment functions among groups divided by organizational type.

\section{ANALYSIS AND CONCLUSION}

\subsection{General}

The questionnaire survey has collected useful information for analysis about user requirements to functionalities of CCEs. It aims to elicit requirements from the targeted user groups in different positions and from different ranges of organizations. Specifically, it emphasizes on gathering the attitude and expectation of the contractors and architects' perspectives. 
The survey shows that, although traditional means of information transfer and communication still dominant, newer electronic means are now on the way to become an alternative approach of communication in the construction industry.

Survey also shows that the use of CCEs had been acknowledged by the users. More than half of respondents had the experiences in using such systems, covering different positions of respondents and organizations in different types and sizes. However, the attitude and expectation to the systems' functionalities varied. Some respondents perceived functionalities of CCEs good enough whilst slightly more respondents were not satisfied. Also, some major features were well acknowledged but the others were not from the respondents' feedback. Overall, respondents did not show a common agreement to the functionalities provided by the existing systems.

One-way ANOVA was conducted according to the organization type organization size of respondents. Significant differences among different groups were found in the respondents' requirements for CCEs system management function, document management function, workflow management function, communication and add-ons. In terms of user requirements for the system management function, respondents of different organizational sizes had varied views on the Project inbox/notice board. Specifically, companies with more than 250 employees needed this function more. Survey participants from different types of organizations held different views on user hierarchical profiling, multi-projects support, project inbox/notice board, project wizard/template, and access control/monitor: For example, compared to architectural firms and sub-contractors, engineering firms had more positive views on user hierarchical profiling, project inbox/notice board and project wizard/ template. Nearly $100 \%$ of engineering firms chose these functions. On the contrary, compared to other types of organizations, engineering firms had lower demand for multi-projects support and access control/monitor system management functions. In terms of user demand for document management functions, companies with a size of more than 250 employees had greater demand for file upload/ download, remote viewing, and notification of change/new, and printing out, indicating that larger companies pay more attention on document management. respondents of different organizational types had significantly different views on file upload/download, remote viewing, mark-up/revise, notification of change/new, search tools, printing out, multi-format file support and disaster protection. For example, compared to other types of organizations, engineering firms had greater requirements for mark-up/revise, notification of change/new, search tools, multi-format file support and disaster protection. On the contrary, they had little requirement for remote viewing. In terms of user requirements of workflow management function, respondents of different organizational sizes had significant differences only in the requirements of process management. Specifically, enterprises with less than 50 employees paid more attention on process management. There were significant differences in the opinions of respondents of different organization types on Integrated project calendar and report on workflow. For example, compared to other organization types, engineering firms do not need Integrated project calendar and report on workflow, but general contractor paid more attention on these two functions. In communication and add-on functions of user demand, different organization scale survey shows significant differences exist. Among them, companies with less than 50 employees paid more attention on instant messenger (IM), health and safety files, while larger companies paid less attention on them, indicating that IM, healthy and safety files by small companies are required more than the others. The system supplier of CCEs should make sure these functions for small companies are provided.

\subsection{Classification of Features From Users' Perspectives}

This survey provides evidence to classify the functionalities of CCEs from user perspectives. The results show that users are mostly concerned on the security of CCEs. All features related to security, including system's safety and document's protection, have drawn much attention from users in the survey. These features, including user authentication, access control, system enabled security, file 
encryption, file archival and disaster protection, should be considered essential and taken into account for a successful product.

The survey also shows that document management is the major and principle function for the users adopting CCEs. Almost all features associated with this function were given higher priority by the users, including file upload / download, file sharing / publishing, mark-up / revise, notification of change / new, search tool, track record / history, printing-out, multiple format support, and file storage / archival. In conjunction with the features in system administration module that facilitate document management, it proves that the users view the effective usage and control to CCEs as essentially important characteristic of using such systems.

The survey results further suggests that compatibility issue should be considered in CCEs. On the one hand, users prefer to manage multiple projects in a single product. They also need to view multiple formats of documents without having to use additional software / plug-ins. On the other hand, the requirement of file storage / archival implied that users needed to use the data generated in the projects either for further reference or for migrating to another system. Therefore, the compatibility of various products is put forward to. This also raises the issue of standardization stated by previous studies (Dawood et al., 2002, Becerik, 2003).

In addition, the survey demonstrates the interest of users in some new features that could possibly be integrated into CCEs in the future. E-tendering and workflow integration would be good examples. Although they have not received higher priority from users' choice, more than one third of respondents would prefer them to be essential features in the systems.

Survey results have shown higher acknowledgement of users to mature technologies such as e-mail. In contrast, the results also show the lower user acceptance to some new tools like instant messaging, audio/video conferencing, hand-held devices and web-cam facility. This suggests that the new technologies are not mature or suitable for use at the corporate level. It also gives the evidence that users in the construction industry are lagging behind the new technology and are not savvy to adopting new tools (Hosseini et al., 2012). However, there were some positive feedbacks to some extent. The advancement of technologies may bring the changes to the adoption of these tools in the future.

The investigation of user requirements has provided evidences to classify the features of CCEs from users' perspectives. The author has therefore grouped the features into three categories: most wanted features, wanted features and optional features. This classification is based on the percentages of all optional features. All features gained more than $50 \%$ ratio are ranked as the most-wanted category. The features rated between $30 \%-50 \%$ are ranked as wanted features. All the rest are ranked optional feature. Then, the classification is shown in Table 6.

Table 6. Classification of features according to respondents' attitude

\begin{tabular}{|c|c|c|c|c|c|c|}
\hline \multirow[t]{8}{*}{ Most-wanted } & Profiling & Directory & Dashboard & Multi-project & Notice board & Access control \\
\hline & \multicolumn{2}{|l|}{$65.3 \%$} & $54.5 \%$ & $75.2 \%$ & $50.5 \%$ & $52.5 \%$ \\
\hline & Security & File load & Encryption & Sharing & Notification & Search \\
\hline & $53.5 \%$ & $76.5 \%$ & $51.0 \%$ & $78.4 \%$ & $56.9 \%$ & $69.6 \%$ \\
\hline & Track record & Printing & Multi-format & Revise & Storage & Calendar \\
\hline & $56.9 \%$ & $51.0 \%$ & $52.0 \%$ & $53.9 \%$ & $58.8 \%$ & $69.6 \%$ \\
\hline & Process & Change order & Event & E-mail & & \\
\hline & $67.6 \%$ & $54.9 \%$ & $52.9 \%$ & $83.3 \%$ & & \\
\hline \multirow[t]{4}{*}{ Wanted } & Client-end & Customization & Viewing & Disaster & Workflow re & $\mathrm{TQ} / \mathrm{RFI}$ \\
\hline & \multicolumn{2}{|l|}{$30.7 \%$} & $46.1 \%$ & $46.1 \%$ & $49.0 \%$ & $41.2 \%$ \\
\hline & Messenger & Forum & Web-cam & e-Tendering & Template & Conferencing \\
\hline & $33.3 \%$ & $42.2 \%$ & $32.4 \%$ & $42.2 \%$ & $32.7 \%$ & $31.4 \%$ \\
\hline \multirow[t]{2}{*}{ Optional } & Hand-held & Localization & $\mathrm{H} \& \mathrm{~S}$ files & Int-Workflow & & \\
\hline & $22.8 \%$ & $15.8 \%$ & $25.5 \%$ & $29.4 \%$ & & \\
\hline
\end{tabular}




\subsection{Recommendation and Limitations}

In this survey, users were investigated of their attitudes towards functionalities of CCEs via questionnaire surveys. By selecting and investigating some respondents from the target groups (i.e., architects and contractors), users' requirements to the functionalities of CCEs are elicited. Together with previous study aiming to investigate systems' provisions (Liu et al., 2011), our research has examined the systems' provisions and user requirements respectively. Through the investigations, the authors are able to list and classify the features of CCEs. From the first impression, the authors have found that there are some common points, as well as some differences, on the functionalities from system vendors and users' perspectives. Further research is therefore needed to find what the differences there are, to demonstrate the relationships of systems' vendors and users' choices, and to produce a list of major components from both sides. Through this comparison, the researchers can also effectively find the match or gap between system provisions and user requirements to the functionalities and also conclude the primal results regarding this issue, e.g. their difference and commonness, or the possible new provisions from the systems and / or reveal the users' unfulfilled needs.

Like other questionnaire survey, although the author has made efforts to remain the survey unbiased, it's not always possible to judge and manage the respondents' motivation and behavior. For example, it is difficult to avoid the respondents to cater for the items listed in the questionnaire and neglect their other needs in mind. The geographical restriction of respondents may also be another limitation.

Despite the limitations stated, this research was undertaken independently. The authors have also paid emphasis on eliciting the user requirements in a reasonable way and great care was applied in interpreting the results as well. Therefore, the outcomes of this research shouldn't be biased in any way and should give some insights to the user requirements to current implementation of CCEs

\section{ACKNOWLEDGMENT}

This work was partly financially supported by the Chongqing Natural Science Foundation Project of CSTC2011BB2107, CSTC2018jcyjAX0005 and Chongqing Social Science Planning General Project (2017YBGL153). 


\section{REFERENCES}

Becerik, B. (2003). Project EXTRANETS. Harvard University.

Becerik, B. (2004). A Review on Past, Present and Future of Web Based Project Management \& Collaboration Tools and Their Adoption by the US AEC Industry. International Journal of IT in Architecture. Engineering and Construction, 2, 233-248.

Becerik, B. \& Pollalis, S. N. 2006. Computer Aided Collaboration in Managing Construction. Harvard Design School.

Breetzke, K., \& Hawkins, M. (2002). An Introduction to Project Extranets and E-procurement. RICS.

Charalambous, G., Demian, P., Yeomans, S., Thorpe, T., Peters, C., \& Doughty, N. BIM and Online Collaboration Platforms - An Investigation into Emerging Requirements. In K. Gidado (Ed.), Proceedings of the International Conference on Engineering, Project, and Production Management, Brighton, UK, September 10-11. Academic Press. doi:10.32738/CEPPM.201209.0004

CICA. (2003). Guidance on the Introduction and Use of Construction Extranets - Vendor Survey. CICA.

Dawood, N., Akinsola, A., \& Hobbs, B. (2002). Development of Automated Communication of System for Managing Site Information Using Internet Technology. Automation in Construction, 11(5), 557-572. doi:10.1016/ S0926-5805(01)00066-8

Girden, E. (1992). ANOVA: Repeated measures. Thousand Oaks, CA: Sage Publications, Inc. doi: $10.4135 / 9781412983419$

Gliem, J. A., \& Gliem, R. R. (2003). Calculating, Interpreting, And Reporting Cronbach's Alpha Reliability Coefficient For Likert-Type Scales. Proceedings of the 2003 Midwest Research to Practice Conference in Adult, Continuing, and Community Education, Columbus, OH, October 8-10. Ohio State University.

Hosseini, M. R., Chileshe, N., Zuo, J., \& Baroudi, B. (2012). Approaches for implementing ICT technologies within construction industry. Australasian Journal of Construction Economics and Building Conference Series, $1,1-12$.

Liu, N., Kagioglou, M., \& Liu, L. An Overview of the Marketed Functionalities of Web-Based Construction Collaboration Extranets. Proceedings of the International Conference on Information Science and Technology, Nanjing, China, March 26-28. Academic Press.

Lou, E. C. W., \& Alshawi, M. (2008). Critical Success Factors for e-tendering Implementation in Construction Collaborative Environments: People and Process Issues. ITCon, 14, 98-109.

NCCTP. (2006). Proving Collaboration Pays - Study Report NCCTP, UK.

Nitithamyong, P., \& Skibniewski, M. J. (2004). Web-based Construction Project Management Systems: How to Make Them Successful? Automation in Construction, 13(4), 491-506. doi:10.1016/j.autcon.2004.02.003

Raol, J. M., Koong, K. S., Liu, L. C., \& Yu, C. S. (2002). An Identification and Classification of Enterprise Portal Functions and Features. Industrial Management \& Data Systems, 102(7), 390-399. doi:10.1108/02635570210439481

Ruikar, K., Anumba, C. J., \& Carrillo, P. M. (2005). End-user Perspectives on Use of Project Extranets in Construction Organisations. Engineering, Construction, and Architectural Management, 12(3), 222-235. doi:10.1108/09699980510600099

Sommer, R., \& Sommer, B. (2002). A Practical Guide to Benavioral Research. Oxford: Oxford University Press.

Tam, C. M. (1999). Use of the Internet to Enhance Construction Communication: Total Information Transfer System. International Journal of Project Management, 17(2), 107-111. doi:10.1016/S0263-7863(97)00077-X

Wilkinson, P. (2005). Construction Collaboration Technologies - The Extranet Evolution. UK: Taylor \& Francis.

Wilkinson, P. (2008). The Role of Extranets in Construction e-Business. In C. J. Anumba \& K. Ruikar (Eds.), e-Business in Construction. Oxford, UK: Wiley-Blackwell. doi:10.1002/9781444302462.ch6 
Yan, J. (2013). Study on Targeted Marketing of Real Estate Corporations based on Big Data. Marketing Weekly, 9. (in Chinese)

Zou, P. X. W., \& Roslan, B. A. (2005). Different Perspective Towards Using Web-Based Project Management Systems in Construction: Large Enterprises Versus Small-and Medium-Sized Enterprises. Architectural Engineering and Design Management, 1(2), 127-143. doi:10.1080/17452007.2005.9684589

Zowghi, D. \& Coulin, C. (2005). Requirements Elicitation: A Survey of Techniques, Approaches, and Tools. In Engineering and Managing Software Requirements. Berlin: Springer.

Ruoyu Jin's main research interests focus on building information modelling (BIM) pedagogy, construction safety education, construction waste management especially recycled aggregate concrete, and off-site manufacturing for construction. In recent years, Ruoyu has been working on funded research projects related to: (1) applications of digital technologies in off-site manufactured building foundation prototype; and (2) BIM and virtual reality to enhance construction employees' behavioural safety performance. Ruoyu is also continuing the educational research of BIM in collaborating with international partners in embedding BIM in the curriculum of construction management. Specifically, BIM education can be extended from a single module to digitalisation in the programme perspective. The BIM pedagogical studies will maintain the cycle of research-informed teaching and teaching-informed research. 